\title{
Evaluation of flash temperatures of a composite elastomer tip seal with a dry sliding conditions in contact with a high carbon steel plate
}

\author{
I. Tzanakis \& M. Hadfield
}

Sustainable Design Research Centre, School of Design, Engineering and Computing, Bournemouth University, UK

\begin{abstract}
One of the most important issues in dry sliding contact is the frictional heat generated. This study investigates the flash temperatures caused by frictional heating of sliding parallel pairs: a high performance fluoroelastomer composite with a high carbon steel plate. These materials have industrial applications and in particular as the main contacting components within a scroll expander system. The expected flash temperature values of the studied contacts are important to be revealed in order to predict the wear mechanisms associated with excessive contact temperatures caused by sliding friction. Two different roughness profiles of the high carbon steel plate were used. The flash temperatures generated by the asperities contact of the tested materials were investigated as a function of the friction coefficient, the applied pressure and the sliding velocity, using a reciprocating tribometer. Initially physical experimental observations of the specific contact produced with a high- precision thermal camera integrated with a sliding micro-friction machine were conducted. Analytical results using conventional mathematical methodology were also produced. The analytical and experimental findings were then compared indicating interesting correlations within the flash temperatures and the experimental conditions. The most influential parameter for the flash temperature rise is determined.
\end{abstract}

Keywords: flash temperature, roughness, composite elastomer, sliding wear, frictional heat. 


\section{Introduction}

Scroll expander systems are widely used in mechanical applications characterised by dry or lubricated sliding conditions. Typical examples are micro-CHP systems, electrical generators and air-conditioners. Many of these scroll devices facing wear and cavitation problems because of their long operational period, their complicated geometry, their mechanical design and their high-speed working fluids. Tzanakis et al. $[1,2]$ has identified the main wear and cavitation mechanisms responsible for the severe damage of the tip seal and the steel plate of the scroll expander. Apart from cavitation and sliding wear, frictional heating can also play an important role on the tribological behavior of a scroll expander system.

Frictional heating can cause surface temperatures to reach the melting or softening temperature of polymer materials resulting in a drastic change in friction and wear rates [3, 4]. In the contact spots frictional energy is dissipated and plastic deformation occurs. Flash temperatures are generated which are considerably in excess of the bulk and the average temperature of the apparent contact area. This rise of the surface temperature can influence the surface geometry leading to severe local wear and lubrication breakdown. The ability to predict and measure the surface temperatures of the actual contacting bodies is important in order the failure mechanisms of various tribological components like the tip seal and the steel plate of the specific scroll to be avoided. A considerable number of papers dealing with frictional heating and flash temperatures of various materials under dry and lubricated conditions, have been published [5-7]. Effects on the applied load, sliding velocity and testing time were most commonly considered. Furthermore, surface roughness parameters are likely to influence the distribution of temperature rise in a sliding contact. Many studies have shown that the friction coefficient of polymers rubbing against metals decreases with increasing the applied load and the sliding speed due to the generation of thermal effects in the contact spots [8,9]. An extensive work has made by Person [10] where he developed a theory which describes the influence of the flash temperature on rubber friction for various roughness profiles including different velocity and load parameters. Additionally, Guha using a pin on disk apparatus has observed that the surface temperature for six different roughness pairs of sapphire pin against a steel disk increases monotonically with roughness [11].

In this study flash temperature caused by frictional heating generated by the sliding of two parallel pairs: a high performance fluoroelastomer composite tip seal against a high carbon steel plate. The main objective is to study the effect of sliding velocity, contact load and roughness profile on the contact temperature rise. Two different roughness profiles of the steel plate were used in order the thermal effects by the asperities contact to be evaluated. A direct measurement of the flash temperature is virtually impossible since their location within the apparent contact area is continuously changing [12]. Thus, analytical results using conventional mathematical formulas were correlated with the experimental outcomes. When real contact area is considered, the contact is isolated between 
the fibres of the composite elastomer and the steel surface, results were justified a good correlation between the measured flash temperatures and the temperature distribution over the real contact spots.

\section{Experimental procedure}

Several sets of laboratory tests utilising the main parts of the scroll were conducted to study the friction mechanisms and the surface temperature rise of the tested samples (figure 1). The composite tip seal and the steel plate of the scroll used to perform sliding tribological tests using a TE 77 micro-friction machine. The steel plate sample is a high carbon steel material $(0.95 \%$ carbon $)$ with a length of $15 \mathrm{~mm}$. The tip seal is a composite fluoroelastomer material in a matrix of a fluorine mixture reinforced with ceramic particles of $\mathrm{Al}_{2} \mathrm{O}_{3}$ and $\mathrm{SiO}_{2}$ (figure 1). The nominal area of contact of the tip seal samples is $25 \mathrm{~mm}^{2}$ and the average area of the ceramic particles is $200 \mu \mathrm{m}^{2}$. The tests were performed in a room temperature environment.

The micro-friction machine operates by sliding a lower-plate sample in a reciprocating motion against a fixed sample pin. The slider (steel plate) is mounted on a support lower holder connected to the actuator (lower shoulder). The pin sample sits inside the upper holder. The upper holder is fixed in the upper shoulder of the system. The pin is connected via a feedback mechanism to a transducer to provide friction force feedback. Additionally, a high precision IR camera (Flir 3000) was installed in a close distance $(10 \mathrm{~cm})$ to the actual contact. The specific thermal camera has a temperature range of $-20^{\circ} \mathrm{C}$ to $+2000^{\circ} \mathrm{C}$ with an accuracy of $\pm 1 \%$ or $1^{\circ} \mathrm{C}$ for measurement ranges up to $+150^{\circ} \mathrm{C}$. The system has a thermal sensitivity of $20 \mathrm{mK}$ at $30^{\circ} \mathrm{C}$ and measures the infrared radiation (IR) coming from the examine contact unit with a resolution better than $0.1^{\circ} \mathrm{C}$. A spectral range of 8 to $9 \mu \mathrm{m}$ with a resolution of $320 \times 240$ pixels provides colour pictures. Any friction and thermal results at the contact points were evaluated during post-test analysis. Figure 2 shows a schematic of the wear bench-test machine.

The surface preparation of the steel plate was mainly by grinding and lapping. Experiments were carried out using two different Ra values of the steel plate: $0.25 \mu \mathrm{m}$ and $0.5 \mu \mathrm{m}$. $\mathrm{Ra}$ is the average roughness of all points from a plane fit to
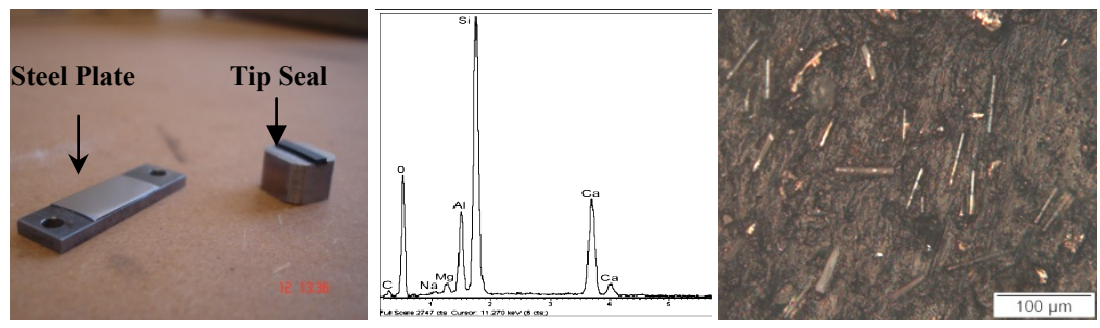

Figure 1: a) The tested samples; b) EPMA analysis of isolated fibres within the fluoroelastomer tip seal; c) Typical area of the tip seal composite. 
the test part surface for a given profile of length L. For the composite tip seal roughness was $3.5 \mu \mathrm{m}$ for all the set of experiments. Two different sliding velocities were used at $0.25 \mathrm{~m} / \mathrm{sec}$ and at $0.5 \mathrm{~m} / \mathrm{sec}$. A contact force of $20 \mathrm{~N}$ and $40 \mathrm{~N}$ is applied using a spring loaded lever arrangement. Run-in time period is decided to be $30 \mathrm{~min}$ so steady state thermal effects to be developed. All the tests performed under dry sliding conditions. Since the primary interest is the temperature in the immediate vicinity of the contact, all the neighbouring surfaces are well insulated avoiding any thermal defects from the surrounding materials.

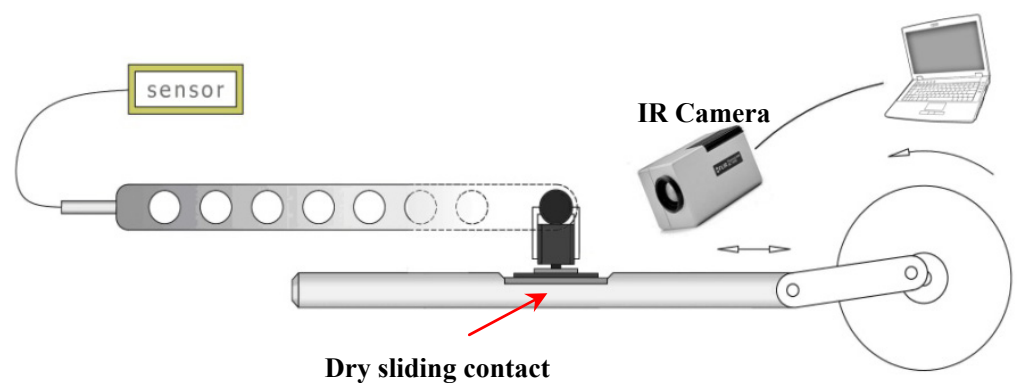

Figure 2: $\quad$ Schematic of the friction apparatus intergraded with an IR camera.

With the use of the TE 77 micro-friction machine, a continuous contact within the two materials avoiding a large part of the heat to be convected is achieved. In a reciprocating movement with high surface velocities, steady state temperatures are uniformly distributed across the contact in a very short period of time. In contrast to the pin on disk experiments where the cooling effects of the incoming cooler and the tested environment playing a critical role in the calculations. Thus the measurements of the flash temperatures within the contact of the tested materials are more accurate. Thermal energy which is not removed from the interface raises the temperature locally.

\section{Experimental results}

A number of experiments using different combinations of load, velocity and surface roughness were carried out. In order to obtain meaningful and comparable data a repeatable test regime was required. Thus, each of the tests was carried out a minimum of 3 times. An example with a series of thermal images (figures 3 and 4) show the effect of the sliding velocity and roughness profile on the actual surface temperature. The hot areas are clearly visible across the contact surfaces showing a tendency of the frictional heat to be accumulated within the mass of the elastomer bulk material. The temperature of the elastomer sample is aggravated since thermal effects dominate soften the contact while the poor thermal conductivity of the elastomer restrains the dissipation of the accumulated frictional heat.

Specifically, as the velocity increases thermal effects are elevated and the real contact area between the contact bodies tends to increase due to thermal 


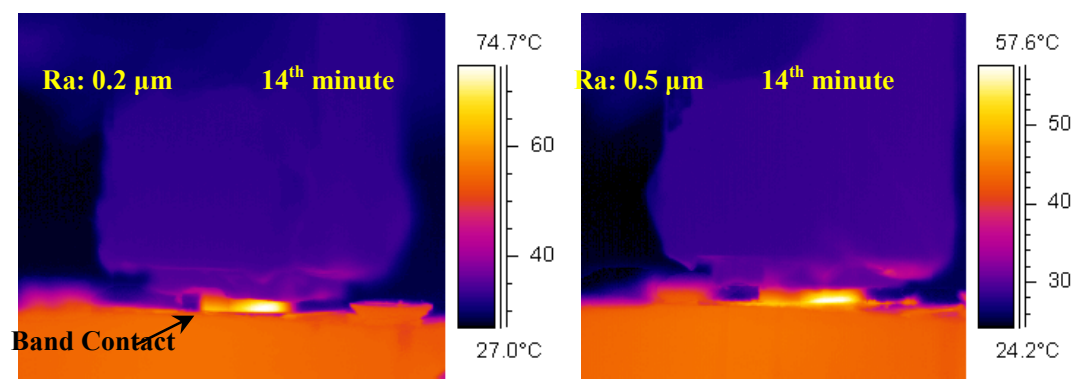

Figure 3: Experimental flash temperature of the contact unit at $25 \mathrm{~Hz}$ and $40 \mathrm{~N}$.

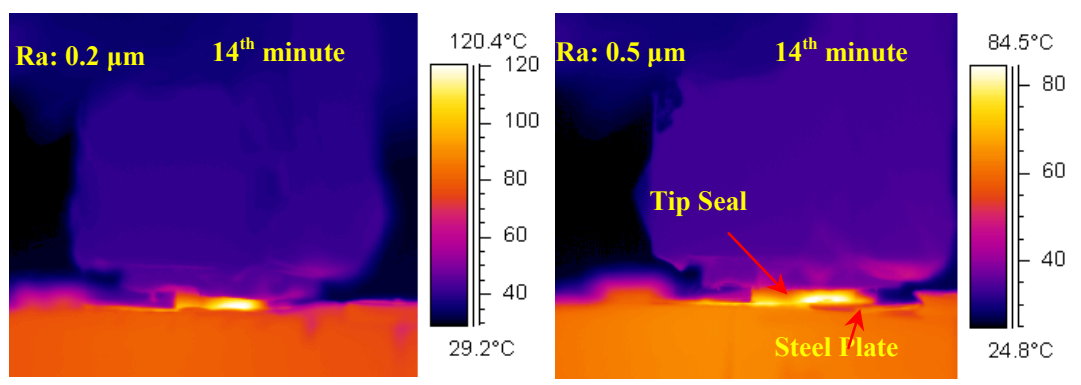

Figure 4: Experimental flash temperature of the contact unit at $50 \mathrm{~Hz}$ and $40 \mathrm{~N}$.

expansion of the elastomer. Consequently, hot spots are multiplied leading to higher flash temperature values. In the case of the steel sample with roughness profile of $0.25 \mu \mathrm{m}$, the change in sliding velocity from $0.25 \mathrm{~m} / \mathrm{sec}$ to $0.5 \mathrm{~m} / \mathrm{sec}$ rises the temperature nearly $45^{\circ} \mathrm{C}$. In contrast when roughness profile of $0.5 \mu \mathrm{m}$ was used, flash temperature increased up to $30^{\circ} \mathrm{C}$. Thus it can be seen that surface roughness seriously affects the increment of surface temperature. In particular, in the case where roughness was at $0.25 \mu \mathrm{m}$, flash temperatures of the macro-asperity contact where generally higher than the corresponding ones with roughness of $0.5 \mu \mathrm{m}$. When velocity was kept at $0.25 \mathrm{~m} / \mathrm{sec}$ the increment of flash temperature between the two roughness profiles was up to $20^{\circ} \mathrm{C}$ while when velocity increased to $0.5 \mathrm{~m} / \mathrm{sec}$ the flash temperature difference reached $35^{\circ} \mathrm{C}$.

In order for the thermal behaviour of the rubbing material to be evaluated a series of graphs showing the relationship of the flash temperature rise with the sliding time and the friction coefficient for different applied loads, sliding velocities and roughness profiles are presented (figures 5 and 6). In all the figures it can be seen that the friction coefficient increases rapidly, in the very first stage of the sliding test while it then stabilises to a steady-state level when thermal effects become active. The thermal effects cannot be instantaneously 

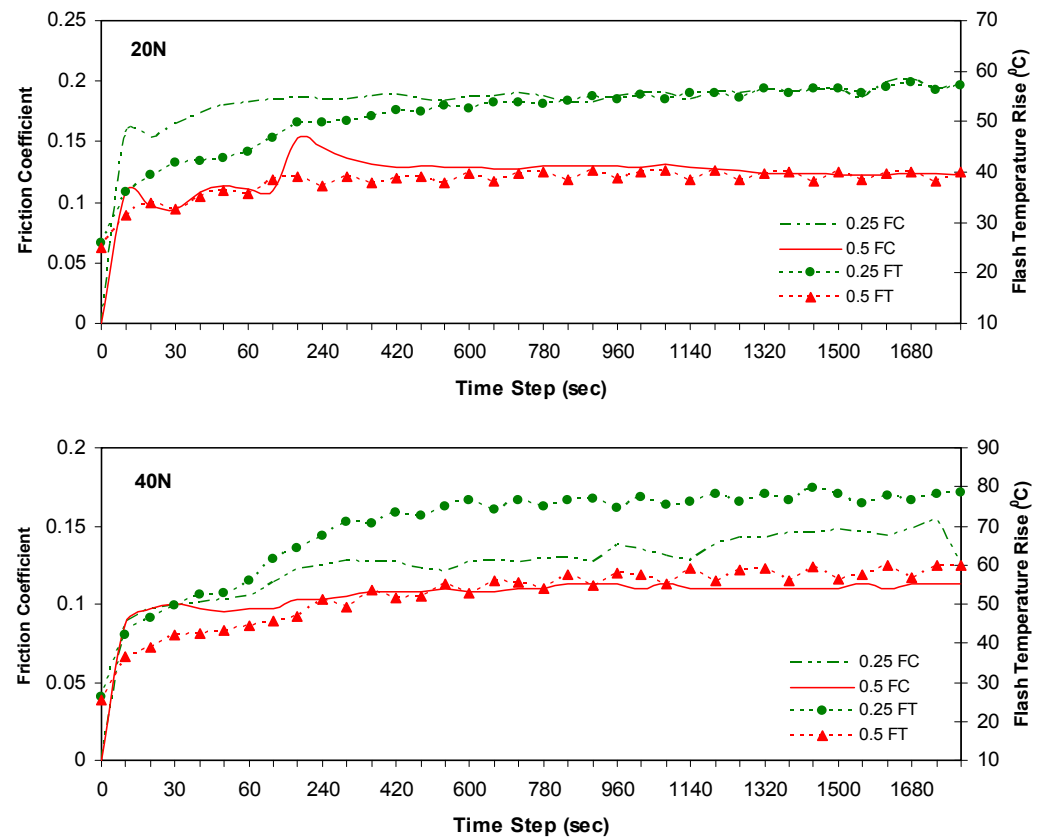

Figure 5: Experimental steady-state friction coefficient (FC) and flash temperature (FT) during an increasing applied load and surface roughness test at $0.25 \mathrm{~m} / \mathrm{sec}$ sliding velocity, in a dry contact at $24^{\circ} \mathrm{C}$.

generated, softening the substrate of the elastomer, thus contact is more severe initially. However after the end of the running-in stage (first 60 seconds) thermal effects dominate and a steady friction regime is achieved.

Figure 5 presents the variation of frictional coefficient with the rise of the flash temperature for $0.25 \mathrm{~m} / \mathrm{sec}$ sliding velocity at two different applied load levels, $20 \mathrm{~N}$ and $40 \mathrm{~N}$. It can be seen that with the increment of the applied load from 20 to $40 \mathrm{~N}$ friction coefficient is slightly reduced while flash temperature significantly increases for both roughness profiles. Specifically in the case with roughness $0.25 \mu \mathrm{m}$ the friction coefficient drops from 0.19 to 0.13 while the flash temperature rises from $55^{\circ} \mathrm{C}$ to nearly $80^{\circ} \mathrm{C}$. Correspondingly for the sample with roughness 0.5 as the load increases the friction coefficient drops insignificantly to a value of 0.11 from 0.13 while the flash temperature is risen up to $20^{\circ} \mathrm{C}$ from around $39^{\circ} \mathrm{C}$ to nearly $60^{\circ} \mathrm{C}$.

In figure 6 friction coefficients are reported as a function of flash temperatures for sliding velocities $0.5 \mathrm{~m} / \mathrm{sec}$. Two different applied loads at 20 and $40 \mathrm{~N}$ and surface profiles at $0.25 \mu \mathrm{m}$ and $0.5 \mu \mathrm{m}$ were used. Similarly to figure 5 it can be noted that flash temperature increases with sliding velocity and the applied load although is substantially reduced with the increase of surface roughness. The flash temperatures reach very high values; more than $120^{\circ} \mathrm{C}$ in 
the case of $40 \mathrm{~N}$ load, accelerating the shearing mechanism of the elastomer. Since the glass temperature of the polymer is around $115^{\circ} \mathrm{C}$ a surface film with different thermal and mechanical properties than those of the substrate is likely to be developed due to shearing of the elastomer material. Consequently, an elastomer layer having a dual role of acting as a cushion and as a thermal insulator it will not only affect the coefficient of friction, but also the dissipation of thermal energy. The elastomer film accumulates frictional heat within the rubbing surfaces while simultaneously reduces friction coefficient values.

In figure 7 a comparison of the tested parameters was conducted in order to evaluate their impact factor on the flash temperature values. Figures 5 and 6 reveal four different cases according their tested parameters. Results indicate the percentage of influence of the sliding velocity, the applied load and the surface roughness on the generation of thermal effects for all the tested cases. Flash temperature is significantly influenced by the sliding velocity rather than the applied load and surface roughness. When sliding velocity is doubled keeping all the other parameters constant the flash temperature increased to about $37 \%$. In contrast, when applied load and surface roughness is doubled the flash temperature is increased to about $29 \%$. Thus comparing the influence of each parameter in the friction regime it can be deduced that sliding velocity plays an overwhelming role in local heating and thus in determination of the surface flash temperature.
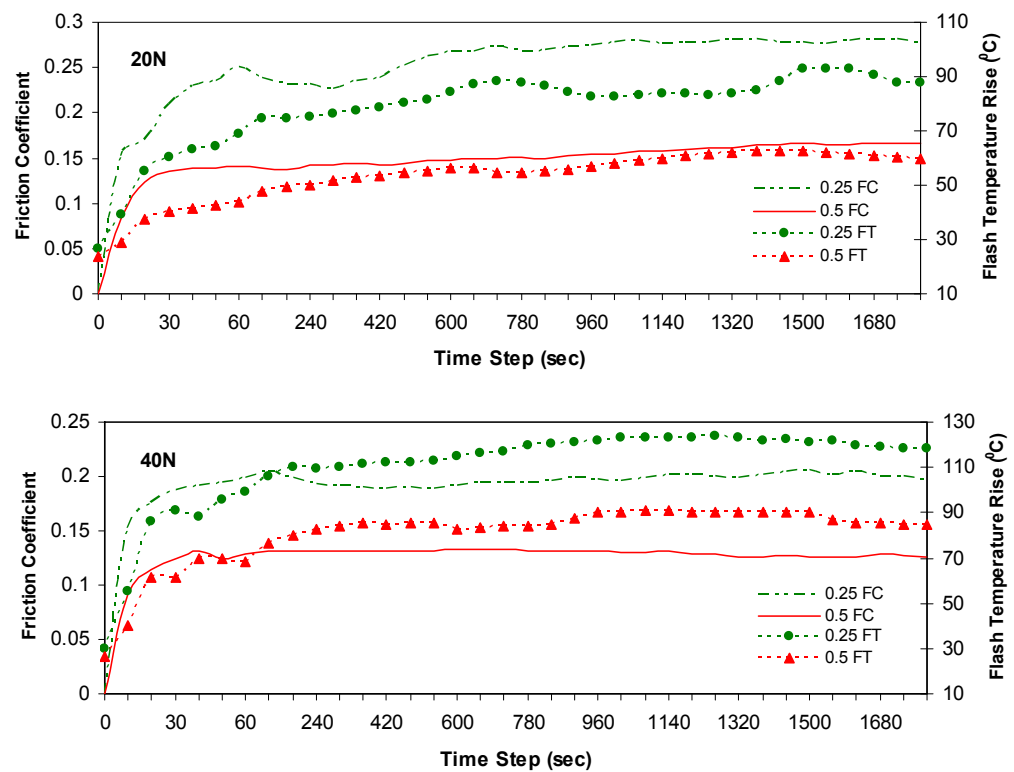

Figure 6: Experimental steady-state friction coefficient (FC) and flash temperature (FT) during an increasing applied load and surface roughness test at $0.5 \mathrm{~m} / \mathrm{sec}$ sliding velocity, in a dry contact at $24^{\circ} \mathrm{C}$. 


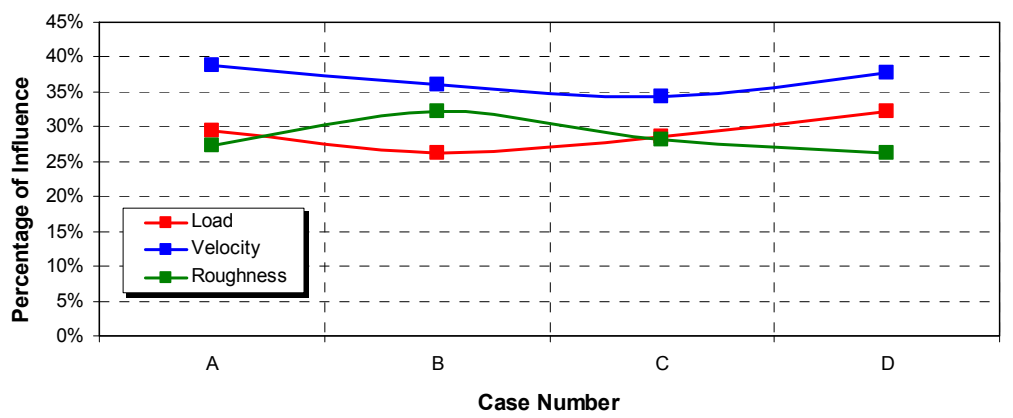

Figure 7: Percentage of influence of velocity, load and roughness on the flash temperature rise for each case number.

\section{Theoretical flash temperature}

The theoretical flash temperature is calculated using conventional mathematical models which developed by Blok [13], Jaeger [14], Ashby et al. [15], Bowden and Tabor [6] and Tian and Kennedy [17]. These theoretical models are supposed to predict the magnitude of flash temperature from certain input data. However, experimental validation of these models often shows that there is a big discrepancy between the measured and the calculated values. For the specific sliding materials the steady state models of Blok, Jaeger and Tian were taken into consideration showing a better approach to the actual contact.

Table 1: $\quad$ Thermal properties of contacting materials.

\begin{tabular}{|c|c|c|c|}
\hline $\begin{array}{c}\text { Thermal Conductivity } \\
\left(\mathbf{W} / \mathbf{m}^{\circ} \mathbf{C}\right)\end{array}$ & $\begin{array}{c}\text { Specific Heat Capacity } \\
\left(\mathrm{J} / \mathrm{kg}^{\circ} \mathrm{C}\right)\end{array}$ & $\begin{array}{l}\text { Thermal Diffusivity }\left(10^{-5} \mathrm{x}\right. \\
\left.\mathrm{m}^{2} / \mathrm{sec}\right)\end{array}$ & $\begin{array}{r}\text { Density } \\
\left(\mathrm{kg} / \mathrm{m}^{3}\right)\end{array}$ \\
\hline 50 & 450 & 1.43 & 7800 \\
\hline 0.4 & 1000 & 217 & 2300 \\
\hline
\end{tabular}

Initially, the theoretical flash temperature using the macro-asperity contact of the sliding units is determined. The most representative model of flash temperature for that specific case is the band contact model of Tian and Kennedy [17]. The system of interest is the surface of the elastomer composite sliding against the high carbon steel plate. It was assumed that all the frictional work goes into heat, entering the two surfaces and producing temperature rise in both. The temperature rise is the flash temperature reached for a very short time at the contacting asperities during sliding. In the case where the micro-asperity contact was taken into consideration the flash temperature rise by the asperities contact of the elastomer fibres against the asperities of the steel plate is determined. Flash temperatures may be estimated using the approach developed by Jaeger [14]. Jaeger followed Blok's [13] work proposes two solutions for the flash temperature of a moving surface relative to a square heat source of half width $b$. 
One solution is for a moving or stationary surface and one for a surface moving at high speed. In the same concept are the solutions proposed by Tian and Kennedy [17]. The results from both models are in a very good agreement and used for the calculation of flash temperatures generated by the micro-asperity sliding contact of the fibres with the steel sample.

The thermal density flow $\mathrm{q}\left(\mathrm{W} / \mathrm{m}^{2}\right)$ per unit area of the contact is given by the expression $\mu \mathrm{Pu}$ where $\mu$ is the measured friction coefficient, $\mathrm{P}$ is the mean contact pressure $(\mathrm{MPa})$ and $\mathrm{u}$ is the sliding speed $(\mathrm{m} / \mathrm{sec})$. Peclet number $(\mathrm{Pe})$ is a non dimensional measure of the speed showing the ratio of thermal energy contacted to that convected.

$$
P e=\frac{u b}{2 \chi}
$$

where $\chi\left(\mathrm{m}^{2} / \mathrm{sec}\right)$ is the thermal diffusivity of each surface defined as $\mathrm{K} / \rho \sigma$ (where $\rho\left(\mathrm{kg} / \mathrm{m}^{3}\right)$ is the density and $\sigma$ is the specific heat $\left(\mathrm{J} / \mathrm{kg}{ }^{\circ} \mathrm{C}\right.$ ). At higher speeds, convection prevails and equations for $\mathrm{Pe}>5$ are used to calculate flash temperature rise. At low speeds, conduction is dominant and the expressions for $\mathrm{Pe}<0.1$ are used to calculate flash temperature rise. In the case of the band contact higher Peclet numbers Pe $>5$ were achieved while in the case of the square contact within the fibres of the tip seal and the steel plate Peclet number fell in the range of $\mathrm{Pe}<0.1$. In any of the cases Greenwood's equation [18] was used to interpolate between the calculated slow and fast temperature regimes.

In order to calculate the potential flash temperature generated across the specific contact, the thermal properties of the materials has to be defined (table 1). The thermal properties of the high carbon steel sample were provided by the manufacturer. However for the elastomer tip seal due to its complicate composite nature the values shown are estimates based on the literature.

Figure 8 shows the calculated flash temperature of the macro-asperity contact over the rate of frictional work. It can be seen that flash temperature rises slightly, maximum 1.2 degrees indicating a relaxed sliding contact. There is a big gap between the calculated results and the experimental measured with the IR camera. This can be explained by the fact that elastomer is an easily deformable material and hence able to absorb a lot of energy, due to its visco-elastic deformation component and its higher specific heat capacity. Additionally, the high thermal diffusivity of the steel restricts the accumulation of thermal effects lowering the calculated flash temperature values. Nevertheless in this study the energy partition into other forms such as noise, vibrations, material deformation, creation of new surfaces by adhesion is not considered. The thermal models are focused on the interface and not on the thermal impedance of the surrounding equipment like heat flow into the fixtures, forced convection and radiation. Thus it is hardly appropriate to calculate flash temperature using the above equations.

However, in the case where micro-asperity contact from the elastomer fibres is considered the models seems to work well (figures 9 and10). The results are in a good correlation with a similar work made by Varadi et al. [19]. Varadi using FE micro-models studied the sliding motion of different carbon fibres orientations against a steel asperity. In figure 9 the results from the calculated 


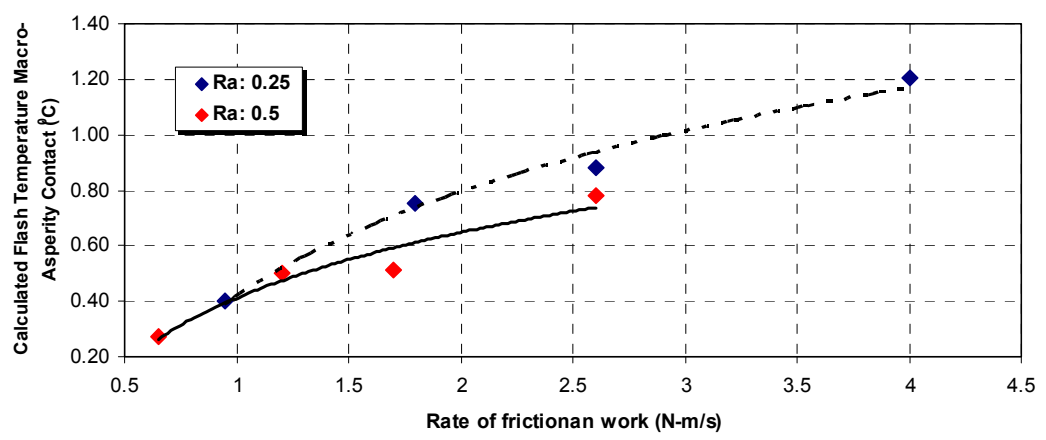

Figure 8: Calculated flash temperature rise against the rate of frictional work for two different roughness profiles.

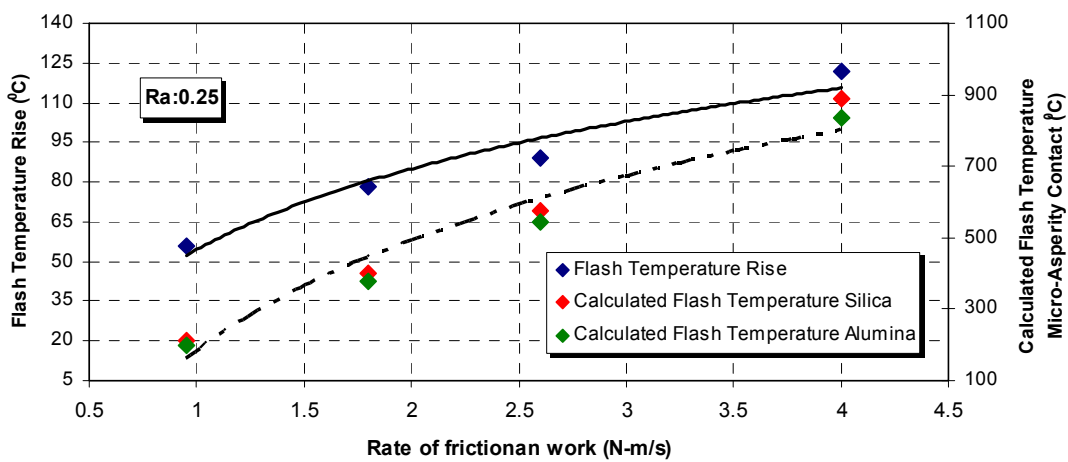

Figure 9: Experimental flash temperature rise of the actual contact and calculated micro-asperity flash temperature of the silica and the alumina fibres against the rate of frictional work ( $\mathrm{Ra}: 0.25 \mu \mathrm{m})$.

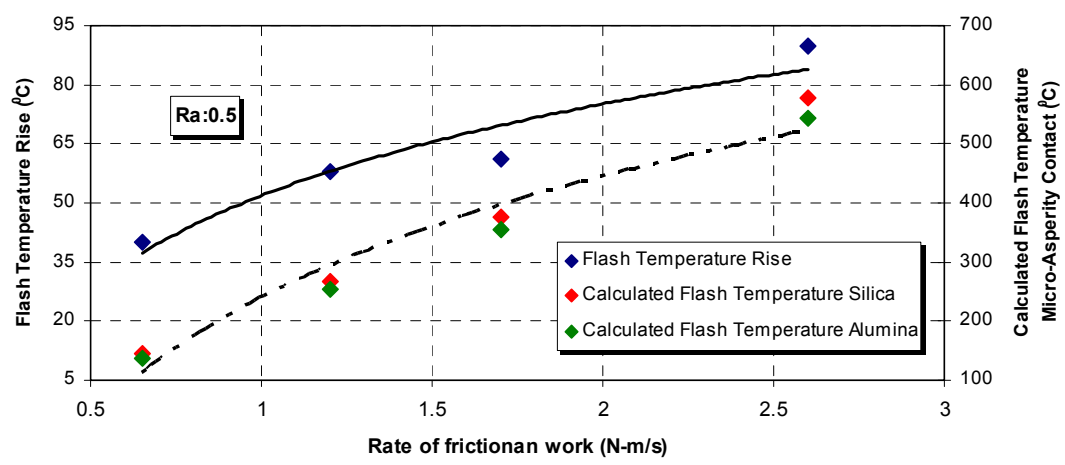

Figure 10: Experimental flash temperature rise of the actual contact and calculated micro-asperity flash temperature of the silica and the alumina fibres against the rate of frictional work (Ra: $0.5 \mu \mathrm{m})$. 
flash temperature micro-asperity contact over the rate of frictional work are depicted. It can be seen that in both figures the graph is a monotonically increasing function for both experimental and theoretical approaches, while the influence of roughness is noticeable. In figure 10 where roughness was at $0.25 \mu \mathrm{m}$ flash temperature was calculated to be up to $900^{\circ} \mathrm{C}$, in contrast to the case where roughness was at $0.5 \mu \mathrm{m}$ and flash temperature rises to nearly $600^{\circ} \mathrm{C}$. These temperatures can become critical for the operation of scroll expanders or similar automotive industrial units since heat can be carried away by lubricant and debris increasing the wear rate and the degradation process of the oil in a micro-contact level.

\section{Conclusions}

In the present study the flash temperature rise during the dry sliding contact of a composite elastomer against a high carbon steel plate was investigated with means of high precision thermal imagery using various combinations of sliding velocities 0.25 and $0.5 \mathrm{~m} / \mathrm{sec}$, applied loads 20 and $40 \mathrm{~N}$ and surface profiles 0.25 and $0.5 \mu \mathrm{m}$. Results have shown that:

Friction coefficient increases with sliding velocity while it is substantially reduced with the increment of the roughness profile and the applied load. In contrast flash temperature significantly rises with the applied load lowering the friction coefficient levels while it also increases with the augmentation of the sliding velocity and the attenuation of the surface roughness.

The most influential parameter for the flash temperature rise within the specific contact was found to be sliding velocity. The impact of the sliding velocity has on the specific contact can be up to $37 \%$ in contrast to the applied load and the surface roughness which both are nearly to $29 \%$.

The experimental findings and the theoretical flash temperature calculations have shown that the rate of frictional work monotonically increases within the macro- and micro-asperity contact. However, the calculated flash temperature values of the macro-asperity contact are not in agreement with the experimental results. When micro-asperity contact is evaluated, results indicate a flash temperature rise of up to $900^{\circ} \mathrm{C}$. In such a high temperature regimes the main components of a scroll expander system can be seriously affected while frictional heating changes the shear strengths of the materials and in the case of lubricated sliding can result in the breakdown or failure of the lubricant.

\section{References}

[1] Tzanakis, I., Hadfield, M., Georgoulas, A., Kotsovinos. N. (2010). "Cavitation damage observations within scroll expander lubrication systems," Third International Conference of Tribology and Design, pp. 261-273. ISBN: 978-1-84564-440-6

[2] Tzanakis, I., Hadfield, M., Khan. Z. (2009). "Durability of domestic scroll compressor systems," Ninth International Conference of Surface Effects and Contact Mechanics, 62 pp. 229-240. ISBN: 978-1-84564-186-3 
[3] Kennedy, F.E. and Tian, X. (1994). The effect of interfacial temperature on friction and wear of thermoplastics in the thermal control regime, in Dissipative Processes in Tribology Dowson, D. et al. (Eds.), Elsevier Science, Amsterdam, 235.

[4] Tzanakis, I., Hadfield, M., Hensaw, I., Garland, N., Khan, Z. (2011). Experimental Sliding Performance of Composite Tip Seal with HighCarbon Steel Plate under Lubricated Conditions Applied to Scroll Expander Systems. Tribology Transactions, Volume 54 Issue 4, (505-513).

[5] Mitjan Kalin (2004). Influence of flash temperatures on the tribological behaviour in low-speed sliding: a review. Materials Science and Engineering A, 374 (390-397).

[6] Sutter, G., Ranc N. (2010). Flash temperature measurement during dry friction process at high sliding speed Wear, 268 (1237-1242).

[7] Ingram, M., Reddyhoff, T., Spikes H. A. (2011). Thermal Behaviour of a slipping wet clutch Tribology Letters, 41 (23-32).

[8] Wieleba W. (2005). The role of internal friction in the process of energy dissipation during PTFE composite sliding against steel Wear, 258 (870876).

[9] Li Chang and Klaus Friedrich (2010). Enhancement effect of nanoparticles on the sliding wear of short fiber-reinforced polymer composites: A critical discussion of wear mechanisms Tribology International, 43 (2355-2364).

[10] Persson B. N. J. (2006). Rubber friction: role of the flash temperature J. Phys.: Condensed Matter 18 (7789-7823).

[11] Guha, D., Chowdhuri S. K. Roy (1996). The effect of surface roughness on the temperature at the contact between sliding bodies, Wear 197 (63-73).

[12] Berry, G. A., Barber. J. R. (1984). The division of frictional heat-A guide to the nature of sliding contact. Journal of Tribology 106 (405-415).

[13] Blok. H. (1937). Theoretical study of temperature rise at surfaces of actual contact under oilness lubrication conditions. Inst. Mech. Eng. General Discussion on Lubrication, 2 (222-235).

[14] Jaeger. J. C. (1942). Moving sources of heat and temperature at sliding contacts. Proc. R. Soc. 76 (203-224).

[15] Ashby, M. F., Abulawi, J., Kong, H. S. (1997). On surface temperatures at dry sliding surfaces, Cambridge University Press.

[16] Bowden F. P. and Tabor, D. The friction and lubrication of solids, Clarendon Press, Oxford, 1964.

[17] Tian, X. and Kennedy, F.E. (1994), Maximum and average flash temperatures in sliding contacts, ASME J. Tribol., 116, 167-174.

[18] Greenwood, J. A. (1991). An interpolation formula for flash temperatures. Wear 150 (153-158).

[19] Varadi, K., Neder, Z., Friedrich, K. (2004). FE contact and thermal analysis of composite surfaces with different fibre orientations subjected to a sliding steel asperity Finite Elements in Analysis and Design 40, (1475-1497). 